\title{
Howard Temin Award, Guidelines
}

National Cancer Institute

\section{Source}

National Cancer Institute. Howard Temin Award, Guidelines. NCI Thesaurus. Code C18840.

This five year career development award provides a mechanism for bridging the transition from a mentored research environment to an independent research career for scientists who have demonstrated unusually high potential during their initial stages of training, career development and are focusing on human disease. 